\title{
Eudragit NE30D Based Metformin/Gliclazide Extended Release Tablets: Formulation, Characterisation and in Vitro Release Studies
}

\author{
Enose Appavoo Arno, ${ }^{a}$ Prithiviraj AnAnd, ${ }^{a}$ Kesavan Bhaskar, ${ }^{a}$ Somasundaram Ramachandran, ${ }^{a}$ \\ Muniyandy SARAVANAN, ${ }^{*, a}$ and Radhakrishnan $\operatorname{VINOD}^{b}$ \\ ${ }^{a}$ Department of Pharmaceutics, Vel's College of Pharmacy; P.V.Vaithialingam Road, Old Pallavaram, Chennai-600117, \\ India: and ${ }^{b}$ Mederich Sterilab Pvt Ltd., Bangalore-560062, India.
}

Received May 23, 2002; accepted August 28, 2002

Metformin/Gliclazide extended release tablets were formulated with Eudragit NE30D by wet granulation technique. Two batches were prepared in order to study influence of drug polymer ratio on the tablet formation and in vitro drug release. The formulated tablets were characterized by disintegration time, hardness, friability, thickness, weight variation, and in vitro drug release. The percentage of polymer, with respect to Metformin/Gliclazide, required to produce tablets with acceptable qualities was 9 to 13.45. The percentage of polymer below this range released the drug immediately and above this range produced granules not suitable for tablet formation. The quantity of Metformin/Gliclazide present in the tablets and the release medium were estimated by a validated HPLC method. The formulated tablets had acceptable physicochemical characters and released the drug over $6-8 \mathrm{~h}$. The data obtained from in vitro release studies were fitted with various kinetic models and was found to follow Higuchi kinetics.

Key words Eudragit NE30D; Metformin/Gliclazide; HPLC; extended release tablets; release kinetic

Metformin hydrochloride and Gliclazide are oral hypoglycemic agents ${ }^{1)}$ belonging to biguanide group and secondgeneration sulphonyl urea respectively. Generally, they are individually used in the treatment of type II non-insulin dependent diabetes mellitus. The combination of both the drugs are also available and it is reported ${ }^{2)}$ to be effective than individual therapy. Metformin acts ${ }^{3)}$ by decreasing hepatic glucose production and improves insulin sensitivity by increasing peripheral glucose uptake. Because of its shorter and variable biological half-life ${ }^{4,5)}$ of $1.5-4.5 \mathrm{~h}$, it should be repeatedly administered $(500 \mathrm{mg}$ thrice a day) to maintain effective plasma concentration. Gliclazide reduces ${ }^{6}$ the glucose level by direct stimulation of insulin release from beta cells of pancreatic islet. Relatively Gliclazide is having longer biological half-life $(6-15 \mathrm{~h})$ depending upon individual and the dose ${ }^{7)}$ is $80 \mathrm{mg}$ two-three times a day with meals. Combination of Metformin-500 mg and Gliclazide- $80 \mathrm{mg}$ per tablet is available in India and it is to be taken two to three times a day to get required effect.

In the present study, we attempted to formulate Metformin/Gliclazide extended release tablet by using Eudragit NE30D aqueous dispersion, with an intention to extend the drug release over a period of $8-12 \mathrm{~h}$, hence it can be taken once a day. The formulated tablets were analysed for drug content by a validated HPLC technique developed in our laboratory and characterized by various physicochemical parameters such as disintegration time, hardness, friability, thickness, weight variation and in vitro drug release.

\footnotetext{
Materials and Methods

Materials Metformin hydrochloride and Gliclazide (gift samples from Mederich Sterilab Pvt Ltd., Bangalore, India), Eudragit NE30D (Rohm Pharma, GmbH, German), Colloidal anhydrous silica (Pioma Chemical Ltd., India), dibasic calcium phosphate (Citorgia Biochemicals Ltd., Vishakhapatnam, India), polyvinylpyrrolidone (PVP K30, ISP, International Corporation, Mumbai). All reagents used were of either HPLC or analytical grade.

Formulation of Tablets The extended release tablets were formulated by using wet granulation technique. The Metformin hydrochloride was passed through sieve \#100. Gliclazide, dibasic calcium phosphate, colloidal anhydrous silica and PVP K30 were passed separately through sieve \#40.
}

Then the required amount of powders as given in Table 1 were mixed in a 101 capacity rapid mixer-granulator (Rotamix HSMG-10, Kevin Engineers, India) for $5 \mathrm{~min}$. Then the required quantity of Eudragit NE30D was added in divided portions to the mixed powder and the granulation was done in rapid mixer granulator for $3 \mathrm{~min}$. Eudragit NE30D was as a binder and as well as polymer to extend the drug release. The granules obtained were kept at $40^{\circ} \mathrm{C}$ for $30 \mathrm{~min}$ in a tray drier (Bombay Engineering Works, India). At semi dried condition the granules were passed through sieve \#14 and then dried at $40^{\circ} \mathrm{C}$ until loss on drying becomes $2.5 \%$ in IR balance (Advanced Ltd., Mumbai, India). Finally, the granules were lubricated with magnesium stearate, colloidal anhydrous silica and compressed using $20.5 / 12.5 \mathrm{~mm}$ oval shape punches in 10-station rotatory compression machine (Clit, Mumbai, India).

Determination of Metformin/Gliclazide Content by HPLC The percentage of Metformin/Gliclazide present in the tablets were determined by a validated high performance liquid chromatography technique developed in our laboratory. Twenty tablets were powdered and the quantity equivalent to $125 \mathrm{mg}$ of Metformin and $20 \mathrm{mg}$ of Gliclazide was weighed accurately and transferred to a $50 \mathrm{ml}$ volumetric flask. To this $25 \mathrm{ml}$ of mobile phase (acetonitrile/methanol/water, $6: 5: 9$, adjusted to $\mathrm{pH} 3.5$ with phosphoric acid) was added. The flask was shaken well to dissolve active medicaments and the volume was adjusted to $50 \mathrm{ml}$ with mobile phase. The solution was filtered through Whatman filter paper (No. 542, pore size $2.7 \mu \mathrm{m}$ ). Five milliliters of the filtrate was diluted with mobile phase in order to get a concentration of $25-50 \mu \mathrm{g}$ of Metformin and 4-10 $\mu \mathrm{g}$ of Gliclazide per $\mathrm{ml}$ and determined at $228 \mathrm{~nm}$. Briefly $20 \mu \mathrm{l}$ of the diluted sample was injected into HPLC, Shimadzu, VP version, consist of ODS $C_{18}$, Hycersil $^{\circledR}, 250 \times 4.6 \mathrm{~mm}$, $5 \mu \mathrm{m}$ particle size column. Acetonitrile/methanol/water $(6: 5: 9)$ adjusted to $\mathrm{pH} 3.5$ with phosphoric acid was used as mobile phase and pumped with help of two LC-10 VP pump (Shimadzu) at the rate of $1 \mathrm{ml} / \mathrm{min}$. The quantity of Metformin and Gliclazide present in the effluent were determined by using SPD-10 AVP UV/Visible detector at $228 \mathrm{~nm}$.

The mean calibration curve of Metformin $(Y=0.1219 x+0.0331)(n=6)$ was linear between 25 and $75 \mu \mathrm{g} / \mathrm{ml}\left(r^{2}=0.9999\right)$. The correlation coefficient of separate calibration curve varied between 0.9985 and 0.9999 . The recovery of the 25,50 and $75 \mu \mathrm{g}$ of Metformin per $\mathrm{ml}$ was $99.4 \pm 6.31 \%$, $96.9 \pm 2.81 \%$ and $94.2 \pm 2.1 \%$ respectively. The retention time, tailing factor and theoretical plates were $0.96 \pm 0.6 \mathrm{~min}, 0.5$ and 692 respectively. The mean calibration curve of Gliclazide $(Y=0.1854 x+0.0126)(n=6)$ was linear between 4 and $12 \mu \mathrm{g} / \mathrm{ml}\left(r^{2}=0.9998\right)$. The correlation coefficient of separate calibration curve varied between 0.9962 and 0.9994 . The gliclazide recovery of 4,8 and $12 \mu \mathrm{g} / \mathrm{ml}$ were $99.2 \pm 3.21 \%, 97.6 \pm 2.91 \%$ and $94.4 \pm 1.16 \%$ respectively. The retention time, tailing factor and theoretical plates was $5.26 \pm 0.3 \mathrm{~min}, 0.99$ and 5133 respectively.

A typical chromatogram of a mixture of Metformin and Gliclazide is shown in Fig. 1. The quantity of Metformin and Gliclazide present in the 
formulated extended release tablet, estimated by the HPLC technique is given in Table 1.

Evaluation of Tablets The tablets were evaluated for their physicochemical characters ${ }^{8)}$ like disintegration time, friability, hardness, thickness, weight variation, and drug content.

In Vitro Release Studies The in vitro release of Metformin and Gliclazide from the formulated tablets was carried out by using $\mathrm{pH} 7.4$ phosphate buffer as the medium in USP dissolution apparatus II (paddle) at $37 \pm 2{ }^{\circ} \mathrm{C}$ and $50 \mathrm{rpm}$. Three milliliters of samples were taken at hourly intervals, diluted with mobile phase, and analysed for drug content at $228 \mathrm{~nm}$ by HPLC method as described above. Three $\mathrm{ml}$ of fresh dissolution medium was added after each sampling.

\section{Results and Discussion}

Variety of Eudragit polymers has been employed in coating ${ }^{9)}$ of Pharmaceutical dosage forms in order to get enteric release or controlled release. Klaus Lehmann et al. ${ }^{9}$ reported controlled release of drug from Eudragit NE30D coated potassium chloride crystals. Choy et al. ${ }^{10)}$ formulated and evaluated Eudragit NE40D buccal patches for controlled release. Genc et al. ${ }^{11)}$ developed dimenhydrinate controlled re-

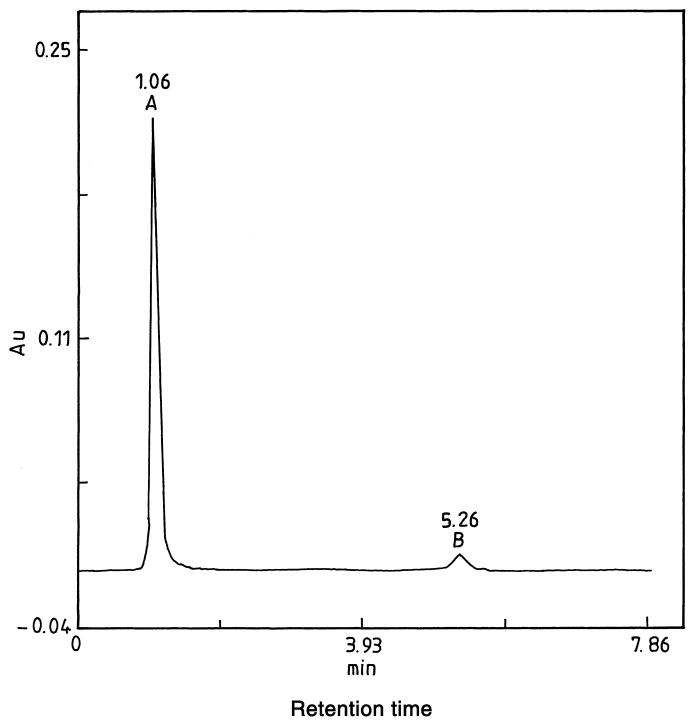

Fig. 1. Typical Chromatogram Showing the Peaks Obtained from a Solution of (A) Metformin $(25 \mu \mathrm{g} / \mathrm{ml})$ and (B) Gliclazide $(4 \mu \mathrm{g} / \mathrm{ml})$ with Retention Time of $1.06 \mathrm{~min}$ and $5.26 \mathrm{~min}$ Respectively

Table 1. Composition and Characteristics of Metformin/Gliclazide Tablets lease matrix tablet by using Eudragit NE30D. In the present study, we attempted to develop Metformin/Gliclazide extended release tablet based on Eudragit NE30D. Since Metformin is having short biological half-life and exhibits a side effect in the GI tract, extended release dosage forms leading to less frequency of dosing would be desirable. Eudragit NE30D is an aqueous dispersion of a neutral, permeable and $\mathrm{pH}$ independent polymer with low tendency of interactions, hence selected for the present formulation.

The tablets were prepared successfully by wet granulation technique by using PVP K30, as it was the only available dry binder effective in low concentration. The formulated tablets had acceptable characteristics. Since Metformin and Gliclazide having the maximum absorbance at $228 \mathrm{~nm}$, the drug content were analysed by a sensitive and reproducible HPLC method developed in our laboratory as explained in the experimental part. The drug content of tablet was uniform and with in acceptable limits. The physicochemical parameters like disintegration time, friability, thickness, hardness, and weight variation of formulated tablets were within the standard limits of Indian Pharmacopoeia as shown in Table 1. As expected, the percentage of Eudragit NE30D in tablet increases, the release of drug from the tablet also extended. This may be due to thick coat of polymer around the drug. Eudragit NE30D, being a binding agent, produces strong binding among granules in higher quantity and prolongs disintegration time of tablets. The increase in disintegration time further favours prolonged release of the drug from the tablets. The batch 1 and 2 extended the drug release up to 6 and $8 \mathrm{~h}$, respectively as shown in Fig. 2. The release profile was found to be biphasic with initial burst effect in the first hour and then the release was slow and extended up to 6$8 \mathrm{~h}$. About 30 to $40 \%$ of Metformin/Gliclazide was released in the first hour and the remaining drug was released slowly over 6 to $8 \mathrm{~h}$.

Ideally, the extended release dosage forms should be designed considering that the drug is having absorption window and exhibits saturation in absorption. If the drug has absorption window, the zero order release is undesirable, where the release rate is constant and independent of drug concentration. This would lead to reduction of bioavailability be-

\begin{tabular}{lcc}
\hline \multicolumn{1}{c}{ Composition per tablet } & Batch 1 & Batch 2 \\
\hline Metformin hydrochloride & $1000 \mathrm{mg}$ & $1000 \mathrm{mg}$ \\
$160 \mathrm{mg}$ \\
Gliclazide & $160 \mathrm{mg}$ & $520 \mathrm{mg}$ of dispersion \\
Eudragit NE30D & $348 \mathrm{mg}$ of dispersion & $156 \mathrm{mg}$ of polymer \\
\cline { 2 - 3 } \% of polymer with respect to drug & $104.4 \mathrm{mg}$ of polymer & 13.45 \\
Dibasic calcium phosphate & $100 \mathrm{mg}$ & $100 \mathrm{mg}$ \\
Colloidal anhydrous silica & $11.6 \mathrm{mg}$ & $11.6 \mathrm{mg}$ \\
PVP K30 & $17.4 \mathrm{mg}$ & $17.4 \mathrm{mg}$ \\
Physicochemical parameters & $43 \pm 2.75 \mathrm{~min}$ & $56 \pm 3.15 \mathrm{~min}$ \\
Disintegration time & $4.4 \pm 0.10 \mathrm{~kg} / \mathrm{cm}{ }^{2}$ & $4.3 \pm 0.27 \mathrm{~kg} / \mathrm{cm}^{2}$ \\
Hardness & $7.12 \pm 0.04 \mathrm{~mm}$ & $7.20 \pm 0.03 \mathrm{~mm}$ \\
Thickness & $0.6 \%$ & $0.7 \%$ \\
Friability & $1321 \pm 39 \mathrm{mg}$ & $1510 \pm 27 \mathrm{mg}$ \\
Average weight & $98.6 \pm 0.95 \% \mathrm{w} / \mathrm{w}$ Metformin & $101.4 \pm 1.32 \% \mathrm{w} / \mathrm{w} \mathrm{Metformin}$ \\
Drug content & $99.2 \pm 1.14 \% \mathrm{w} / \mathrm{w} \mathrm{Gliclazide}$ & $97.8 \pm 1.24 \% \mathrm{w} / \mathrm{w} \mathrm{Gliclazide}$
\end{tabular}


cause of very high local concentration of drug, above its saturation point, at the site of absorption. In such instance Higuchi release is desirable, where the release rate is fast in initial conditions and the release rate will become slower as the time progress, hence the drug concentration always be maintained with in saturation level at the site of absorption and thus produces greater bioavailability. Data obtained from in vitro release (first $80 \%$ release) studies were fitted to various kinetic equations to find out the mechanism of drug release from formulated extended release tablets. The kinetic models used were zero order equation, ${ }^{12)}$ first order equation $^{13)}$ and Higuchi release. ${ }^{14)}$ The following plots were made: $Q_{t}$ vs. $t$ (zero order kinetic model); $\log \left(Q_{0}-Q_{t}\right)$ vs. $t$ (first order kinetic model, figure not shown) and $Q_{t} v s$. square root of $t$ (Higuchi model). Where $Q_{t}$ is the amount of drug released at time $t$ and $Q_{0}$ is the initial amount of drug present in tablets. The best fit with the highest correlation coefficients was shown in Higuchi, first order and followed by zero order equations as given in Table 2 . The rate constants were calculated from the slope of the respective plots. ${ }^{15)}$ The time for $50 \%$ release $\left(t_{50 \%}\right)$ was calculated from respective rate constants by using appropriate half-life equations. ${ }^{14)}$ High correlation was observed in Higuchi plot (Fig. 3) rather than first order and zero order. The drug release was proportional to the square root of time, indicating that the drug release is diffusion controlled and similar observations are reported by

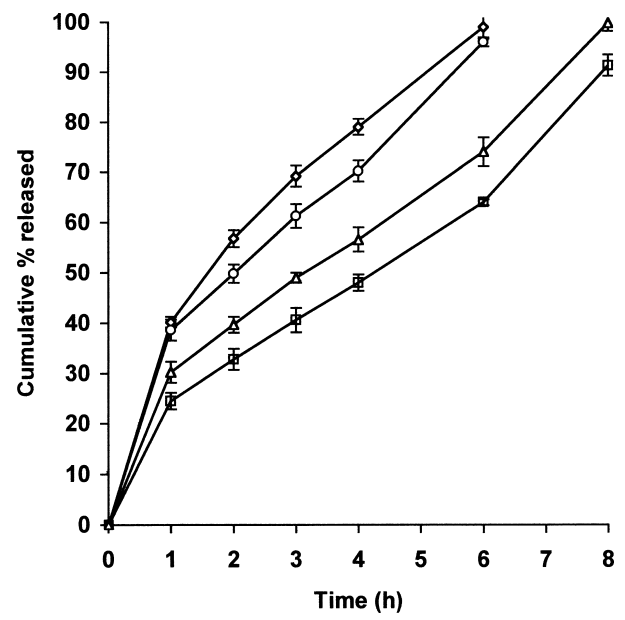

Fig. 2. In Vitro Release of Gliclazide from Batch $1(\diamond)$, Batch $2(\triangle)$ and Metformin from Batch $1(\bigcirc)$ and Batch $2(\square)$ Tablets

Each data represents average of six determinations and bar represents \pm S.D.
Klaus Lehmann et al. ${ }^{9)}$ Plots (Fig. 4) of the release rate $v$ s. $1 /$ Cumulative $\%$ released were linear and plots of the release rate $v s$. percentage released was curved, which confirms ${ }^{16}$ )

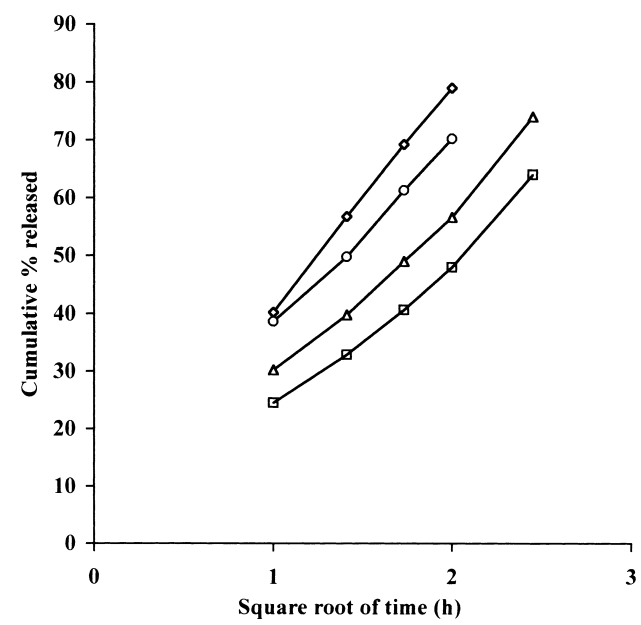

Fig. 3. Higuchi Plot of Gliclazide Release from Batch $1(\diamond)$, Batch $2(\triangle)$ and Metformin Release from Batch $1(\bigcirc)$ and Batch $2(\square)$ Tablets

Each data represents average of six determinations.

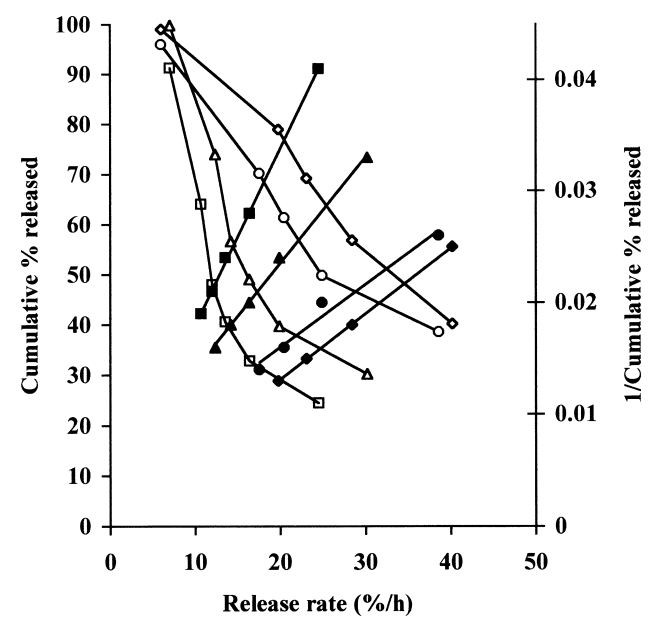

Fig. 4. Plots of Release Rate against Cumulative Percentage Released (Closed Symbols) and Reciprocal of the Percentage Released (Open Symbols)

Gliclazide release from batch 1 and batch 2 was denoted as $(\diamond)$ and $(\triangle)$ respectively, Metformin release from batch 1 and batch 2 was denoted as $(O)$ and $(\square)$ respectively. Each data represents average of six determinations.

Table 2. Release Kinetics of Eudragit NE30D Based Extended Release Tablets

\begin{tabular}{|c|c|c|c|c|c|c|c|c|c|}
\hline & \multicolumn{3}{|c|}{ Zero order } & \multicolumn{3}{|c|}{ First order } & \multicolumn{3}{|c|}{ Higuchi } \\
\hline & $\begin{array}{l}\text { Correlation } \\
\text { coefficient } \\
\left(r^{2}\right)\end{array}$ & $\begin{array}{c}\text { Release } \\
\text { rate } \\
\left(\% \mathrm{~h}^{-1}\right)\end{array}$ & $\begin{array}{l}t_{50 \%} \\
(\mathrm{~h})\end{array}$ & $\begin{array}{l}\text { Correlation } \\
\text { coefficient } \\
\left(r^{2}\right)\end{array}$ & $\begin{array}{c}\text { Release } \\
\text { rate } \\
\left(\% \mathrm{~h}^{-1}\right)\end{array}$ & $\begin{array}{l}t_{50 \%} \\
(\mathrm{~h})\end{array}$ & $\begin{array}{l}\text { Correlation } \\
\text { coefficient } \\
\left(r^{2}\right)\end{array}$ & $\begin{array}{c}\text { Release } \\
\text { rate } \\
\left(\% \mathrm{~h}^{-1}\right)\end{array}$ & $\begin{array}{r}t_{50 \%} \\
\text { (h) }\end{array}$ \\
\hline \multicolumn{10}{|l|}{ Batch1 } \\
\hline Gliclazide & 0.9164 & 19.26 & 2.59 & 0.9938 & 0.3800 & 1.82 & 0.9998 & 39.7 & 1.59 \\
\hline Metformin & 0.8913 & 17.86 & 2.80 & 0.9739 & 0.2856 & 2.43 & 0.9971 & 34.8 & 2.05 \\
\hline \multicolumn{10}{|l|}{ Batch 2} \\
\hline Gliclazide & 0.9189 & 13.27 & 3.76 & 0.9834 & 0.2096 & 3.31 & 0.9955 & 29.4 & 2.89 \\
\hline Metformin & 0.9368 & 11.68 & 4.30 & 0.9838 & 0.1593 & 4.35 & 0.9914 & 25.3 & 3.91 \\
\hline
\end{tabular}

Each data obtained from average of six determinations and $r^{2}$ represents correlation coefficient. Release rate was calculated from the slope of the respective plots and time for $50 \%$ release $\left(t_{50 \%}\right)$ was calculated from respective half-life equations. 
that the release followed Higuchi model.

Disintegration of the tablet in to granule, initially released the surface drug and uncoated drug, as observed by the burst effect with in the first hour, then the remaining drug was released from the granules slowly in zero order pattern. As shown in Fig. 2, the rate of drug release reduced with time, this may be due to the increase in path length through which the drug molecule is diffusing in the granule towards dissolution medium. We also tried to formulate tablets by increasing the ratio of Eudragit NE30D in order to extend the drug release further. Higher percentages of Eudragit NE30D in tablet composition resulted in viscous and cohesive granules with unacceptable characteristics and it was found to be unsuitable for tablet formation. The addition of more amount of Eudragit during granulation stage results in a very wet mass and it requires $2-5 \mathrm{~h}$ drying at 40 to $50^{\circ} \mathrm{C}$, which may influence the stability of the drug. Thus, formed granules were found to be sticky and hard to pass through sieve \#14 and were found to be not suitable for tablet compression. The tablet formulated as per the composition given in Table 1 possesses acceptable characteristics, releases Metformin/Gliclazide over $6-8 \mathrm{~h}$ and was found to be suitable for extended drug delivery.

\section{References}

1) Martindale, "The Complete Drug Reference," 32nd edition, ed. by Kathleen Parfitt, Pharmaceutical Press, London, 1999, pp. 320-330.
2) Galeone F., Fiore G., Arcangeli A., Mannucci E., Minerva-Endoorinal, 23, 71-75 (1998).

3) Andre J. E., Pierre J. L., Drugs, 55, 225-236 (1998).

4) Marchetti P., Navalesi R., Clinical Pharmacokinetics, 16, 100-128 (1989).

5) Abdullah O. Y., Boraie N. A., Naggar V. F., S.T.P. Pharma, 4, 15-20 (1998).

6) Lebovitz H. E., Melander A.,"Sulfonyl Ureas:Basic Aspects and Clinical Uses, in International Textbook of Diabetes Mellitus," 2nd edition, ed. by Alberti K. G. M. M., Zimmet P., Defronzo R. A., Keen H., John Wiley \& Sons Ltd., 1997, pp. 817-857.

7) United States Pharmacopoeia Drug information, United States Pharmacopoeial Convention, INC., Rockville 18th edition, 1998, pp. $272-285$.

8) Indian Pharmacopoeia, Volume II, Controller of Publications, Delhi, 1996, p. 735

9) Lehmann K., Aßmus M., Bössler H., Dreher D., Liddiard C., Petereit H-U., Rothgang G., Weisbrod W., Beckert T., "Practical Course in Film Coating of Pharmaceutical Dosage Forms with Eudragit ${ }^{\mathbb{R}}$," Pharma Polymers, Rohm Gmbh, Darmstadt, Germany, 1999, pp. 1176.

10) Choy F. W., Kah H. Y., Kok K. P., Int. J. Pharmaceut., 178, 11-22 (1999).

11) Genc L., Bilac H., Guler E., Pharm. Acta Helv., 74, 43 - 49 (1999).

12) Bavaja S. K., Ranaga Rao K. V., Padmalatha Devi K., Int. J. Pharmaceut., 39, 435-440 (1987).

13) Wagner J. G., J. Pharm. Sci., 58, 1253-1256 (1969).

14) Higuchi W. I., J. Pharm. Sci., 52, 1145-1149 (1963).

15) Carter S. J. (ed.), “Tutorial Pharmacy,” Nazia Printers, Lal Quan, Delhi (India), 1986, pp. 90-93.

16) Abubakr O. N., Jun S. Z., Drug Dev. Ind. Pharm., 26, 965-969 (2000). 